ment of time, for example, yield stress at 100 sec, or yield stress at $100 \mathrm{~min}$.

Although it might be thought that in blood circulation the flow phenomena must be transient (one complete circulation of the red cell being of an order of 1 min), this is not so in pathological cases (various forms of stasis and intravascular clotting), and the time for one complete circulation might be quite appreciable in these cases.

Finally, I would like to suggest that rheological curves plotted on log-log scales have certain advantages in the micro-rheological ${ }^{5}$ interpretation, as they make it relatively easy to account for the contributions of subphases or phases of blood to the blood viscosity.

This work is being supported by the National Heart Foundation of Australia.

Department of Medicine,

\section{LeOpold Dinteanfass}

University of Sydney,

Australia.

' Charm, S., and Kurland, G., Nature, 208, 617 (1965).

"Dintenfass, L., Circulat. Res., 11, 233 (1964).

${ }^{3}$ Dintenfass, L., J. Lab. and Clin. Med., 64, 594 (1964).

'Dintenfass, L., Rheol. Acta, 2, 187 (1962).

5 Dintenfass, L., Proc. Intern. Symp. Second-Order Effects in Elasticity, Plasticity and Fluid Mechanics, 764 (Pergamon Press, 1964); Proc. Fourth Intern. Cong. Rheol., 621 (John Wiley, New York, 1964).

\section{Fission of Virus and Protein under Electron Bombardment}

IT has been reported ${ }^{1}$ that, provided threshold bombarding energies and current densities are achieved, it is possible to transfer metallic films deposited on an anode to a cathode in vacuo by electron bombardment (a thin film thermionic emitter was used as a detector). The mechanism of release can be considered to arise from $(a)$ an energy conversion yielding thermal evaporation over areas of atomic dimensions of the surface layer, or $(b)$ an indirect one involving ionization in situ and the breaking of metallic bonds of a fraction of the surface atoms.

Recently, a gas-contaminated fine tungsten point was used to detect singly charged positive gas ions between a cathode and an anode ${ }^{2}$; about 400 impacts per sec were recorded at a pressure of $10^{-5} \mathrm{~mm}$ mercury. This work has now been extended to detect the fission into complex atom groups and single atoms as a result of bombarding with electrons, virus and protein material placed on the anode. Pseudomonas bacteriophage was used at a concentration of $7 \times 10^{7}$ virus particles per c.e. There is no a priori reason why the mechanism of detachment in an insulator should differ from that in a metal if the impact is a 'correct' one. To reduce impacts arising from any residual gas, the anode system consisted of a cylindrical box of copper-nickel $20 \mathrm{~mm}$ in diameter, $15 \mathrm{~mm}$ long and with a central $3-\mathrm{mm}$ hole through which a tuft of four thoriated tungsten wires projected for a distance of $3 \mathrm{~mm}$; these were insulated from the box, and faced a finely etched thoriated tungsten point detector, $1 \mathrm{~cm}$ away.

The method used in the experiment was to connect the box and tufts together so as to establish a 'threshold' voltage for gas ionization; if the anode was made 20 per cent negative to the tufts, it rednced the number of single impacts arising from any gas to very small value--something in the order of 20 per sec. An inspection of some 5,000 oscillograph traces showed the usual recovery time and form of the current variations-about $1 \mathrm{msec}$ and 50 per cent, respectively; examples are shown in Figs. I $a$ and $b$. When the tufts were coated with the bacteriophage (about 100 virus particles), there was a time lag of 1-3 min before impacts were detected at the 'threshold', but a steady increase of single impacts up to 300 per sec soon became apparent. This effect is shown in Fig. $2 a$ and indicates that the bonds in the virus and protein material on the tufts had been broken. In actual fact, the anode competes with the detector for the disintegration products and, when bombarded, gives a curve such as is

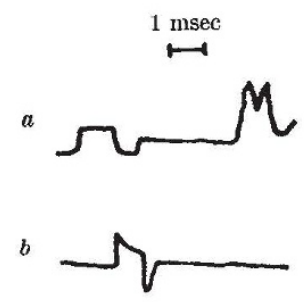

Fig. 1. Single impulses arising owing to the presence of gaseous ions $a$, Anode; $b$, tufts

$$
0.3 \mathrm{msec}
$$

$\mapsto$
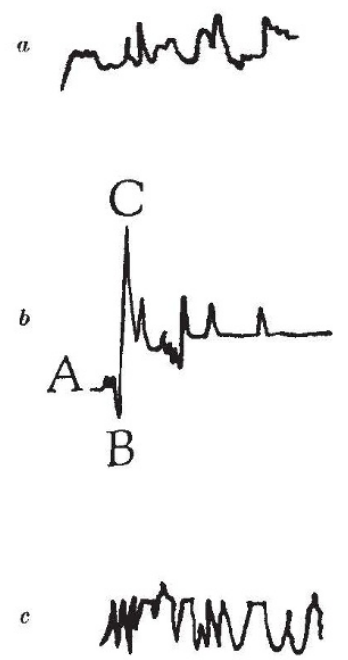

Fig."2. $a$, Single impacts (tufts); $b$, fission products; $c$, successive impacts

shown in Fig. $2 b$, where the current variation is 500 per cent. The extremely small reaction time coupled with excessive variations in current are never recorded with gaseous ions, but it is probable that they arise from the fission of the virus and protein material. A possible interpretation of curve $1 b$ is that the initial portion, $A-B$, arises through the cutting off of the beam as the particles proceed towards the detector; this region thus represents the transit time. Subsequent disturbance on the surface produces the 500 per cent current increase, $B-C$. On the basis that the average recovery time varies inversely as the square root of the mass, the portion $A B C$ represents a fission product of about $400 \AA$ diameter. Subsequent peaks indicate unusual complexes with masses of $40-140$ times that of the oxygen atom. The striking suceession of single ions which originate at a localized point, shown in Fig. 2c, nearly always occur in spasmodic bursts at some stage of the bombardment; this results in the great activity at the detector.

The layer on the tufts is polarized by the field, and may be some $1000 \AA$ thick. This is easily penetrated by the $3-4-\mathrm{kV}$ electrons; the secondary electrons should have sufficient energy to escape, but they are prevented from doing so because there are no fields in the right direction. Thus such electrons pass on their energy to the lattice, and help in breaking the bonds of some of the atoms penetrated. An approximate calculation shows that each primary electron releases $1 / 10^{24}$ of the atoms in the coating.

I thank Dr. Bell of the Department of Microbiology for supplying me with the solution of Pseudomonas bacteriophage for these experiments.

Department of Natural Philosophy,

L. JACOB

University of Strathclyde,

Glasgow, C.1.

${ }^{1} \mathrm{Jacob}, \mathrm{L}$., Nature, 15\%, 586 (1946).

2 Jacob, L., Nature, 198, 774 (1963). 